\title{
Female Education and Health: Effects of Social Determinants on Economic Growth and Development
}

\author{
${ }^{1}$ Shibu John, ${ }^{2}$ Prerna Singh
}

\begin{abstract}
This study aims to discuss about girl's education and health's direct impact on economic growth. Education leads to higher social standing, independence, and greater autonomy in the decision-making process. Educated women will have greater control over family finances as they are more likely to spend discretionary resources on investments in human capital, such as health, education, and food. Desired millennium development goals cannot be achieved unless women are educated and are strengthened to take decisions about their own health in a suitable and conducive environment. This can only be attained by community-based demand side interventions for better education and maternal health. This study suggests that educated women were more likely to contribute to strengthen the economic growth of the nation than uneducated women. Female education level improves the health status of the family, which ultimately leads the economic growth and achievement of social development goals.
\end{abstract}

Keywords: Development, Economic growth, Education, Health indicators, Maternal health.

How to cite this article: John S, Singh P. Female Education and Health: Effects of Social Determinants on Economic Growth and Development. Int J Res Foundation Hosp Healthc Adm 2017;5(2):84-88.

Source of support: Nil

Conflict of interest: None

\section{BACKGROUND}

The impact of girl's education does not limit to individual or one family, but for the complete society. Accordingly, not educating girls has a direct impact both on their families and on society as a whole. A World Bank study analyzes the effect of girls' education in many countries, where it was found that increase in girls' access to education creates a better milieu for economic growth and development, whereas research done in middle and lower income countries examined the impact of female education on gross domestic product, which consistently showed positive effects. Health indicators, such as the

\footnotetext{
${ }^{1}$ Associate Professor, ${ }^{2}$ Consultant

${ }^{1}$ Department of Health and Hospital Management, Jamia Hamdard, New Delhi, India

${ }^{2}$ Public Health Foundation of India, Gurugram, Haryana, India

Corresponding Author: Shibu John, Associate Professor Department of Health and Hospital Management, Jamia Hamdard, New Delhi, India, e-mail: Shibu.john14@gmail.com
}

lower fertility rates among educated women increase a country's annual per capita income growth.

It is evident from a number of studies that large number of girls benefiting from education has a positive effect on a country's per capita income. This is true for both primary and secondary education. The outcome is particularly positive for middle and lower income countries. Thus, communities that do not prefer to invest in girls' education pay a high price for it in terms of lower economic growth and reduced per capita income. Educated women have greater chances to enter the formal labor market, where incomes are higher compared with those of informal or small-scale work. Formally educated female farmers increase productivity and their earnings can exceed those of men. Hence investing in female education and reducing gender biasness lead to economic growth. The social impact of female education is phenomenal.

Another crucial parameter for the growth is maternal health. It is the most important component of public health systems and refers to the health of women during the period of pregnancy, delivery, and postpartum care. Motherhood is often a positive and fulfilling experience, but for many it is associated with pain, ill-health, and even death. Maternal health is an important parameter for the nations due to its influence on women's health, survival of the newborn, and ultimate well-being of children.

The most prominent role of mothers' education is in reducing infant and child mortality, lowering fertility, and promoting children's education. Educated women are better equipped to avoid risky behavior by practicing safe sex. Education leads to higher social standing, independence, and greater autonomy in women's role in decision-making process in the household. Educated women will have greater control over family finances as they are more likely to spend discretionary resources on investments in human capital-health, education, and food. With all these positive impacts on economic and social development, society cannot afford to ignore girls' education. A "coverage gap" can be explained as the percentage of the community not able to access a particular medical intervention out of those who should be getting it.

\section{EDUCATION AS A DETERMINANT OF HEALTH}

Education is a vital determinant of health status in both the developed and developing economies. To consider 
the determinants of health, it is important to understand that poor physical circumstances are not the only factors that cause ill-health, lack of education and awareness can also lead to poor health care accessibility. The high health returns to investing in the education of women are undeniable. Well-educated individuals experience better health care services than the poorly educated, as explained by many self-reported health and low levels of morbidity, mortality, and disability. In contrast, poor educational attainment is linked with high level of infectious disease, self-reported poor health, lower survival rate when diseased, and shorter life expectancy. ${ }^{1}$ Many studies have explained the importance of education for women in improving the overall health of the family. The studies associate education level of women with improved child health and reduced maternal deaths. With time, increasing girls' participation in school, fertility rates decrease. Education helps women in birth planning they should have at what interval. Women with formal education are more likely to carry on career, marry later, and are better informed on the nutritional and other needs of children than illiterate women.

While the exact mechanism of education's influence on health status is not known, it has been recommended that educating women alters the long-established balance of power within the family, leading to changes in decisionmaking process and allocation of resources within the household. ${ }^{2-4}$ Thus, educated mothers are more likely to take advantage of modern medicine and comply with recommended treatments than uneducated women. ${ }^{5}$ Moreover, education may change mothers' knowledge and perception about the importance of modern medicine for the care of their children. In a study of child nutrition in the Philippines, access to health care services benefited children of educated mothers more than children of mothers with less schooling, a finding which suggested that educated mothers were more likely to take advantage of available public health services. ${ }^{6}$

\section{HEALTH INDICATORS THAT AFFECT ECONOMIC GROWTH}

Many factors result in health inequalities, such as socioeconomic status (SES), quality of care, educational attainment, behavior, discrimination, biological and genetic characteristics, and the environment. ${ }^{7}$ India is not unique in displaying inequalities in maternal and child health care. ${ }^{8}$ It is well documented that poor mothers and children do inferior than their better-off peers in health-related outcomes. ${ }^{9,10}$ The risk of maternal and infant mortality and pregnancy-related complications can be reduced by increasing access to quality preconception and inter conception care. ${ }^{11}$ Also, healthy birth outcomes and early management of poor health conditions among infants can prevent death or disability. According to the Census of India 2011, India's percentage of urbanization was $31.15 \%$, whereas average urbanization in high-focus states was $20.73 \% .^{12}$ Despite increasing expenditure on health care and extraordinary medical breakthroughs, the health care system fails to adequately and equally serve many parts of the nation. ${ }^{8}$ Therefore, to achieve sustainable development goals, the coverage of maternal and child health indicators needs to be improved.

Socioeconomic status is a multifaceted term used to characterize one's social position, often defined by income and educational attainment. ${ }^{13}$ Recent studies suggest that SES plays a vital role in health outcomes, access to health care, and overall quality of care. ${ }^{14,15}$ It would be prolific to relate the SES and coverage gap in the Indian context as the nation has a wide diversity in the SES among states. Individuals with a low SES are more likely to experience poor nutrition, inadequate housing with greater exposure to environmental hazards, and all other factors that contribute to poor health.

Education can modify women's beliefs about disease causation and thus influences both childcare practices and the use of modern health care services. ${ }^{16}$ For example, findings from numerous studies of infant and child mortality conducted in developing countries over the last decade show a nearly universal positive association between maternal education and child survival. ${ }^{17-20}$ These facts reveal that women are important promoters of health education and practices within the home, and the benefits of their education extend to their children and others.

Increasing girls' access to education and quality care improves maternal health. In Burkina Faso, mothers with secondary education are likely to give birth more safely in health facilities as compared with those with no education. ${ }^{21}$ It has been assessed that an additional year of schooling for 1,000 women helps in preventing two maternal deaths. ${ }^{22}$ Increasing girls' education has positive results on infant and child health. A child born to a mother who can read is more likely to survive past the age of 5 years than a child born to uneducated woman. In Indonesia, when mothers have no education child vaccination rates were lower with $19 \%$. This figure increases to $68 \%$ when mothers have at least secondary school education. ${ }^{23}$ In Bangladesh and Indonesia, for every additional year of formal education, a mother has the odds of having a child who is shorter than average for its age decreases by around $5 \% .^{24}$

Risk behaviors and social morbidities have produced alarmingly rising rates of health problems in youth. For example, in America, the problems of health illiteracy, low 
self-esteem, and youth risk-taking behavior are becoming more visible in the community and public schools. ${ }^{25,26}$ Schools in the developed and developing world face the challenge of addressing the needs of students who may not be health illiterate and who have significant health needs. $^{27}$

Education decreases woman's risk of contracting human immunodeficiency virus (HIV) or transmitting HIV to her baby. In 32 countries, women who remained in school after primary school were five times more likely to know the basic facts about HIV than illiterate women. ${ }^{28}$ According to the Global Monitoring Report Education for All 2010, in Malawi, only 27\% of women with no education know that HIV transmission risks can be reduced by taking drugs during pregnancy, but that figure rises to $59 \%$ for women with secondary education. ${ }^{23}$ A study in Zambia finds that HIV spreads twice as fast among uneducated girls. ${ }^{28}$ A study in Uganda revealed that each additional year of education for girls reduces their chances of contracting HIV by $6.7 \% .^{29}$

The high case of maternal death in India and across the world continues to warn the well-being of families, ruin economic productivity, and lead to health disparities among communities. The risk of a woman in a developing country dying from a maternal-related cause during her lifetime is about 33 times higher compared with a woman living in a developed country. Maternal mortality is a health indicator that shows very wide gaps between rich and poor, urban and rural areas, both between countries and within them.

The main reasons for maternal deaths within the health system are the lack of skilled birth attendants, remoteness, delay in referral for emergency obstetric care, ${ }^{30}$ delay or poor implementation of interventions at the facility level, and vertical delivery of care in which single elements of care are implemented without connection with the comprehensive care. ${ }^{31}$ Maternal mortality is deeply existed with risk factors, such as low education among mothers, poverty, and gender bias. Poor education and no or low income leave women dependent on their husbands. High levels of illiteracy reduce knowledge about prenatal care and nutritional knowledge, safe pregnancy practices, and family planning methods. Illiterate women often have the least admittance to primary health care and emergency obstetric care. Most health care centers are located in urban area, which cannot be accessed by millions of rural women. On the contrary, illiterate women often experience discrimination and poorer quality care than more educated women. Illiterate women deliver without proper assistance of a skilled birth attendant and less than half deliveries take place in an institution.

\section{ECONOMIC AND SOCIAL CONSEQUENCES}

The consequences of poor education and women health have drastic economic and social implications. A mother is the center of her household and plays an important role for her family. Therefore, her education and health status is a major determinant of her children's upbringing and health. When she dies or is left disabled, her family struggles to survive. The United Nations Children's Fund reports that "infants whose mothers die within the first six weeks of their lives are more likely to die before reaching age two than infants whose mothers survive." This contributes to loss of productive years of upcoming generations, cycles of poverty, and economic losses to the country. Moreover, many obstetric complications due to poor hygiene and nutrition not only cause disability but also ostracize women from their families and communities.

The United Nation's Convention on the rights of the child (1988) and the Millennium Development Goals (2000) committed the international community of governments, international organizations, and nongovernmental organizations to work to provide education for all girls and boys and to eliminate gender disparities at both primary and secondary level. Between 1999 and 2005, 17 additional countries achieved gender parity in primary school attendance, bringing the total proportion that have done so to almost two-thirds (63\%). At secondary level, 19 countries reached gender parity between 1999 and 2005. But only one out of every three countries (37\%) has as many girls as boys at secondary schools. But wide differences remain between different regions and countries and even within countries. Girls still account for $60 \%$ of children out of school in Arab countries and $66 \%$ of nonattendees in South and West Asia. In contrast, more girls than boys attend schools in many countries in Latin America, the Caribbean, North America, and Western Europe.

\section{DEMAND FOR MATERNAL HEALTH CARE}

Maternal health services are dependent on the complex interdependent functioning of the entire health system. ${ }^{32}$ The links between inputs, process, and outcomes are subject to multiple influences and confounding factors and each country's context determines many factors that influence the outcomes of maternal health and the performance of the service. ${ }^{33}$

The intermittent nature of demand, the difficulty in accessing quality maternal health services, and the wide range of powerful stakeholders with different priorities and agendas make the health system extremely complex. ${ }^{34}$ In addition, international donors may influence the conditions of a country's health programs to satisfy their own agenda. ${ }^{35}$ 
Additionally, women need their capacity and capabilities strengthened so that they can take ownership of the decisions about their care at the right time and without having to rely or be expected to rely on others to make these decisions for them. Thus, a strong focus in attaining universal maternal health care access is to overcome demand-side barriers.

\section{HEALTH EDUCATION STRATEGIES}

Some of the strategies that can address the omission of girls in schools include changing the education policies that creates discrimination. This can be done by affirmative action and preferential policies in education, and removing the administrative rules that are considered as barriers. There should be enough efforts toward increasing school supply, establishing community schools, and setting up different choices to formal schooling. Schools should also promote health education on a variety of ways, focusing on biological, behavioral, and pedagogical concepts. Teachers and other health professionals must be prepared to address the complex social, developmental, and health-related issues that are detrimental to economic development of the country. Schools in relatively poor countries face the challenge of addressing the needs of students who may not be health illiterate and who have significant health needs. Continued effort should be made to maximize the learning of critical issues and concepts related to maternal and child health.

\section{CONCLUSION}

In the last few years, substantial progress has been made in girls' education; however, there are lots of issues to be addressed. Despite improvement in girl's basic education level, secondary school enrolment of both boys and girls is poor in most regions. Enrolling girls in higher education requires not just building and staffing more schools, but needs firm political, social, and financial will. Girls' education level improves the health status of the family, which ultimately leads the economic growth and social development goals.

There are a lot of economic and social obstructions when it comes to educating girls. Social exclusion bars certain caste and groups, denying them social rights that ideally should be provided to all citizens. These prejudice leads to poor parental willingness for schooling to girls. Families choose to educate boys over girls, as boys are considered for future employment prospects and the fact that girls in many societies are "married away," and no longer productive in their own families. Most of the developing and underdeveloped world's poor people live in rural areas. Also, transport and distance to school push the opportunity cost of school attendance and the security risk to girls' enrolment to school, and hence restricts school participation.

Education reduces girl's or woman's chances of risking their lives with diseases, which are related to nutritional deficiencies or pregnancy-related complications. Women who live in developing and developed countries and attended higher school were five times more likely to know the basic facts about HIV than uneducated women. Desired millennium development goals may not be achieved unless women are educated in their own communities and are strengthened to take decisions about their own health in a suitable and conducive environment. This can only be attained by community-based demandside interventions for better education and maternal health. There is no doubt that qualified women influence the decision-making process within the family, supporting girls to enroll for higher education and taking suitable employment. Therefore, educated mothers are more likely than uneducated women to contribute toward healthy family and economic freedom to girls. Furthermore, education may change mothers' knowledge and perception of the importance of accessing and spending on family health. This will further suggest that educated mothers were more likely to contribute to strengthen the economic growth of the nation than uneducated mothers.

\section{REFERENCES}

1. Feldman JJ, Makuc DM, Kleinman JC, Cornoni-Huntley J. National trends in educational differentials in mortality. Am J Epidemiol 1989 May;129(5):919-933.

2. Caldwell J. Education as a factor in mortality decline: an examination of Nigerian data. Popul Stud 1979 Nov;33(3):395-413.

3. Caldwell J. Cultural and social factors influencing mortality in developing countries. Ann Am Acad Polit Soc Sci 1990 Jul;510(1):44-59.

4. Caldwell J, Caldwell P. Women's position and child mortality and morbidity in LDCs. Paper presented to IUSSP Conference on Women's Position and Demographic Change in the Course of Development, Oslo. 1988.

5. Schultz TP. Studying the impact of household economic and community variables on child mortality. Popul Dev Rev 1984 Jan;10(Suppl):215-235.

6. Barrera A. The role of maternal schooling and its interaction with public health programs in child health production. J Dev Econ 1990 Jan;32(1):69-91.

7. Adler NE, Ostrove JM. Socioeconomic status and health: what we know and what we don't. Ann N Y Acad Sci 1999 Feb;896:3-15.

8. Ram F, Singh A, Ram U. Human rights approach to maternal \& child health: has India fared well? Indian J Med Res 2013 Apr;137(4):721-727.

9. Bhutta ZA, Chopra M, Axelson H, Berman P, Boerma T, Bryce J, Bustreo F, Cavagnero E, Cometto G, Daelmans B, et al. Countdown to 2015 decade report (2000-10): taking stock of maternal, newborn, and child survival. Lancet 2010 Jun 5;375(9730):2032-2044. 
10. Fenn B, Kirkwood BR, Popatia Z, Bradley DJ. Inequities in neonatal survival interventions: evidence from national surveys. Arch Dis Child Fetal Neonatal Ed 2007 Sep;92(5):361-366.

11. Dean SV, Lassi ZS, Imam AM, Bhutta ZA. Preconception care: closing the gap in the continuum of care to accelerate improvements in maternal, newborn and child health. Reprod Health 2014 Sep 26;11(Suppl 3):S1.

12. ORGI. Census of India. In: Office of the Registrar General Census Commissioner I, ed. Final population totals. New Delhi: Urban Agglomerations and Towns; 2011.

13. Moses T, Liu J. Smoothing and equating methods applied to different types of test score distributions and evaluated with respect to multiple equating criteria. Res Rep 2011 Jun;2011(1):1-25.

14. Boerma JT, Bryce J, Kinfu Y, Axelson H, Victora CG. Mind the gap: equity and trends in coverage of maternal, newborn, and child health services in 54 Countdown countries. Lancet 2008 Apr 21;371(9620):1259-1267.

15. Awasthi A, Pandey CM, Singh U, Kumar S, Singh TB. Maternal determinants of immunization status of children aged 12-23 months in urban slums of Varanasi, India. Clin Epidemiol Glob Health 2015 Dec;3(3):110-116.

16. Schultz TP. Returns to women's education. Economic growth center discussion Paper No. 603. New Haven (CT): Yale University; 1990.

17. Cochrane $\mathrm{SH}, \mathrm{O}^{\prime}$ Hara $\mathrm{DJ}$, Leslie J. The effects of education on health. World Bank Staff Working Paper No. 405. Washington (DC): The World Bank; 1980.

18. Rutstein SO. Socioeconomic differentials in infant and child mortality. WFS Comparative Studies No. 43. Voorburg: International Statistical Institute; 1984.

19. Cleland J, van Ginneken J. Maternal education and child survival in developing countries: the search for pathways of influence. Soc Sci Med 1988;27(12):1357-1368.

20. Cleland J, van Ginneken J. Maternal schooling and childhood mortality. J Biosoc Sci Suppl 1989 Feb;10(Suppl):13-34.

21. UNESCO. EFA global monitoring report: reaching the marginalized. Paris: UNESCO; 2010. [cited 2011 Jul 15]. Available from: http://unesdoc.unesco.org/images/0018/ 001866/186606E.

22. Summers LH. Educating all the children. Policy Research Working Papers Series. Washington (DC): World Bank; 1992.
23. UNESCO. Education counts. Towards the Millennium Development Goals (Paris: UNESCO, 2010), accessed at http:// unesdoc.unesco.org/images/0019/001902/190214e.pdf, on July 20, 2011

24. Semba RD, de Pee S, Sun K, Sari M, Akhter N, Bloem MW. Effect of parental formal education on risk of child stunting in Indonesia and Bangladesh: a cross-sectional study. Lancet 2008 Jan;371(9609):322-328.

25. American Medical Association. America's adolescents: how healthy are they? Profiles of Adolescent Health Series, Vol. 1, Chicago: AMA; 1990.

26. Carnegie Council on Adolescent Development. Turning points - preparing American youth for the 21st century. New York (NY): Carnegie Corporation of New York; 1989.

27. Carnegie Corporation on Adolescent Development. Great transitions - preparing adolescents for a new century. New York (NY): Carnegie Corporation of New York; 1995.

28. Vandemoortele J, Delamonica E. Education vaccine against HIV/AIDS. Curr Issues Comp Educ 2000;3(1).

29. De Walque D. How does the impact of an HIV/AIDS information campaign vary with educational attainment? Evidence from Rural Uganda. Washington (DC): The World Bank; 2004.

30. Campbell OM, Graham WJ. Strategies for reducing maternal mortality: getting on with what works. Lancet 2006 Oct 7;368(9543):1284-1299.

31. Souza JP, Gülmezoglu AM, Vogel J, Carroli G, Lumbiganon P, Qureshi Z, Costa MJ, Fawole B, Mugerwa Y, Nafiou I, et al. Moving beyond essential interventions for reduction of maternal mortality (the WHO Multicountry Survey on Maternal and Newborn Health): a cross-sectional study. Lancet 2013 May;381(9879):1747-1755.

32. Graham WJ. Now or never: the case for measuring maternal mortality. Lancet 2002 Feb;359(9307):701-704.

33. Parkhurst JO, Penn-Kekana L, Blaauw D, Balabanova D, Danishevski K, Rahman SA, Onama V, Ssengooba F. Health systems factors influencing maternal health services: a four-country comparison. Health Policy 2005 Aug;73(2): 127-138.

34. Tayler L. Absorptive capacity of health systems in fragile states. London: HLSP Institute; 2005.

35. Songane F. Stronger national plans for maternal, newborn and child health. Bull World Health Organ 2007 Aug;85(8):577-579. 